\title{
Association of Amino Acid Sequences in the HLA-DQB1 First Domain with the Antitopoisomerase I Autoantibody Response in Scleroderma (Progressive Systemic Sclerosis)
}

\author{
John D. Reveille, * Egon Durban, ${ }^{*}$ Miriam J. MacLeod-St. Clair, ${ }^{*}$ Rose Goldstein, ${ }^{5}$ \\ Ramon Moreda," Roy D. Altman," and Frank C. Arnett* \\ * Division of Rheumatology and Clinical Immunogenetics, Department of Internal Medicine, The University of Texas Health Science \\ Center at Houston, Houston, Texas $77225 ;{ }^{\ddagger}$ Department of Pharmacology, Baylor College of Medicine, Houston, Texas $77030 ;{ }^{\S}$ Division \\ of Rheumatology, Department of Internal Medicine, Ottawa General Hospital, The University of Ottawa, Ottawa, Ontario, Canada; \\ and "Division of Rheumatology, Department of Internal Medicine, The University of Miami School of Medicine, Miami, Florida 33010
}

\begin{abstract}
Previous studies in Caucasians with progressive systemic sclerosis (PSS) have suggested associations of antitopoisomerase I (antitopo I) autoantibodies with either serologically defined HLA-DR2 or DR5. To better define class II HLA associations with the antitopo I response, 161 PSS patients (132 Caucasians and 29 American blacks) were studied for antitopo I autoantibodies by immunodiffusion and immunoblotting, and their HLA-DRB1, DRB3, DQA1, and DQB1 alleles were determined by restriction fragment length polymorphic analysis and DNA oligotyping. Among Caucasians with antitopo I, HLA-DR5(DRB1 *1101-*1104), DRB3*0202 and DQw3 $(\mathrm{DQ} \mathbf{7 , 8 , 9})$ were significantly increased in frequency. In American blacks, however, only HLA-DQB1 *0301 (DQw7) was significantly increased. The presence of HLA-DQB1 *0301 (DQw7) and other HLA-DQB1 alleles bearing the uncharged polar amino acid residue tyrosine at position 30 of the outermost domain was found in all antitopo I-positive Caucasian PSS patients compared with $66 \%$ of antitopo I-negative PSS patients $(\mathrm{pc}=\mathbf{0 . 0 0 7})$ and $70 \%$ of normal controls $(\mathrm{pc}=\mathbf{0 . 0 0 8})$, as well as all antitopo I-positive black patients. The association with HLA-DQB1 was independent of HLA-DR5(DRB1*1101*1104) or any other HLA-DRB1, DRB3, or DQA1 alleles. Alternative or additional candidate epitopes for this autoimmune response include alanine at position 38 and threonine at position 77 of these same DQB1 alleles. These data suggest that genetic predisposition to the antitopo I response in PSS is associated most closely with the HLA-DQB1 locus. ( J. Clin. Invest. 1992. 90:973-980.) Key words: immunogenetics • autoimmunity $\bullet$ nucleoprotein $\bullet$ genotype $\bullet$ autoantigen
\end{abstract}

\section{Introduction}

The cause of progressive systemic sclerosis (PSS), ${ }^{1}$ or scleroderma, is as yet unknown, although both genetic and environ-

Address correspondence to John D. Reveille, M. D., The University of Texas Health Science Center at Houston, P.O. Box 20708, Houston, TX 77225

Received for publication 8 November 1991 and in revised form 23 March 1992.

1. Abbreviations used in this paper: ACA, anticentromere autoantibodies; antitopo I, antitopoisomerase I; OR, odds ratio; PC, corrected $P$ value; PCR, polymerase chain reaction; PSS, progressive systemic sclerosis; RFLP, restriction fragment length polymorphism.

J. Clin. Invest.

(c) The American Society for Clinical Investigation, Inc. 0021-9738/92/09/0973/08 \$2.00

Volume 90, September 1992, 973-980 mental factors have been implicated (1-7). A number of studies have reported associations of HLA antigens with PSS, including $M H C$ class I specificities: $\operatorname{HLA}-A 9(8,9), \mathrm{B} 8(10,11)$, and B35 (12, 13); MHC class II specificities: HLA-DR1 (1316), DR3 (11, 17), and DR5 (16, 18-20); and MHC class III specificities: $\mathrm{C} 4$ null alleles $(12,19)$. These associations have varied among different centers, with some groups unable to show any HLA associations with PSS (21-25).

PSS is a disease in which several highly disease-specific autoantibodies have been defined, which in turn are associated with certain clinical features $(26,27)$. These include anticentromere autoantibodies (ACA), occurring predominantly in the CREST variant or mild scleroderma (26-33); antinucleolar autoantibodies, including anti-PM-Scl, associated with the presence of myositis in PSS patients (34); and antitopoisomerase I (antitopo I), otherwise known as anti-Scl-70, which correlates with widespread skin involvement and systemic disease (26, $27,35)$. Several recent reports have correlated autoantibody subsets more strongly with certain MHC-class II alleles, including ACA with HLA-DR1 (27, 36), DR4 (36), DR5(DRw11) (20), and DRw8 (36); anti-PM-Scl with HLA-DR3 (36); and antitopo I with HLA-DR2 (25) and DR5(DRw11) (27, 36). Few studies, however, have examined the expanded polymorphism at the molecular level now recognized for the adjacent HLA-DQ loci, although one study reported an increased frequency of HLA-DQw7 in patients with ACA (20).

Using restriction fragment length polymorphisms (RFLPs) and oligonucleotide typing of class II MHC alleles, we have reported recently that HLA-DQB1 alleles possessing a polar amino acid (either tyrosine or glycine) at position 26 of the outermost domain constitute the strongest association with the ACA autoimmune response in PSS patients (37). In the present study, we used the same techniques in a large number of PSS patients to compare HLA-DRB1, DRB3, DQA1, and DQB1 alleles in antitopo I-positive and -negative PSS patients and controls to show that the antitopo I response also is correlated most closely with specific HLA-DQB1 chain alleles possessing other shared amino acid sequences.

\section{Methods}

Patients and controls. As an ongoing study, all patients with PSS seen by members of the Divisions of Rheumatology at the University of Texas Health Science Center at Houston (J.D.R., F.C.A.), Ottawa General Hospital, the University of Ottawa (R.G.), and the University of Miami School of Medicine (R.M., R.D.A.) are studied for a variety of autoantibodies and undergo HLA-DR, DQ, and DP typing by RFLP and/or oligotyping methods in the University of Texas Laboratories after informed consent is obtained. To date 161 patients with PSS have been evaluated, including 74 from Houston, 34 from Ottawa, and 44 
from Miami, as well as 9 from Georgia who were part of an epidemiological study reported previously (38). 132 were Caucasian and 29 were American black. In addition, three native Americans (Choctaws) with PSS were investigated. All patients had either PSS by the preliminary criteria formulated by the American College of Rheumatology (39), or the CREST syndrome if at least three out of the five CREST features (calcinosis, Raynaud's phenomenon, esophageal dysmotility, sclerodactyly, and telangiectasia) were observed during the course of the disease.

Normal controls included 200 local Houston Caucasians of predominantly northwestern European ancestry and 88 local American black volunteers who were blood donors or medical school personnel and whose HLA-DR and DQ alleles were defined similarly by RFLP and oligotyping analyses.

Autoantibody determinations. ACA and antinuclear antibodies were determined by indirect immunofluorescence on Hep-2 cells, with positivity defined at serum dilutions $1: 80$ or greater. ACA were detected by the typical immunofluorescent pattern seen on interphase and metaphase nuclei of Hep-2 cell substrate. Antitopo I antibodies were determined by both passive immunodiffusion using calf thymus extract as substrate and by immunoblotting of affinity-purified topoisomerase I from HeLa cell nuclei (E.D.) (40) at the Baylor College of Medicine.

Genetic analysis of $H L A-D R B 1, D R B 3, D Q A 1$, and $D Q B 1$ alleles. Genomic DNA was extracted from peripheral blood leukocytes (41). "Broad" HLA-DR specificities (DR1, DR2, DR3/6, DR4, DR5(DRw11), DR5(DRw12), DR7, DRw8, DR9, and DRw10) were determined either by RFLP analysis of $T a q \mathrm{I}, \mathrm{Bam} \mathrm{HI}$ and $E c o \mathrm{RI}$ digested genomic DNA described previously (42) or by polymerase chain reaction (PCR) amplification of $0.5 \mu \mathrm{g}$ of genomic DNA using the primers DRBAMP-A (5'-CCCCACAGCACGTTTCTTG-3') and DRBAMP-B ( $5^{\prime}$-CCGCTGCACTGTGAAGCTCT-3'). The PCR was carried out for 30 cycles under the following parameters: denaturation $1 \mathrm{~min}$ at $96^{\circ} \mathrm{C}$, annealing $1 \mathrm{~min}$ at $55^{\circ} \mathrm{C}$, extension $2 \mathrm{~min}$ at $72^{\circ} \mathrm{C}$. Hybridization and washing conditions were as described previously (43).

For the RFLP analyses, HLA-DR and DQ specificities were assigned to specific RFLP bands at the 10th International Histocompatibility Testing Workshop (44), as well as in our own $(45,46)$ and others' studies (47-50). Specific HLA-DQA1 and DQB1 chain alleles in each individual were assigned by comparison with reported DQA1 and DQB1 RFLPs for HLA-D haplotypes as determined by the World Health Organization Nomenclature Committee for Factors of the HLA System $(44,51)$.

For HLA-DR5 subtyping, patients and controls positive for HLADR3(DRw17), DR5(DRw11), DR5(DRw12), DRw6(DRw13,14), and DRw8 by RFLP or oligotyping underwent group-specific PCR amplification of DRB1 alleles using the primers DRBAMP-3 (5'CACGTTTCTTGGAGTACTCTAC- $3^{\prime}$ ) and DRBAMP-B under conditions outlined for DRBAMP-A and B, except the annealing step for the PCR was at $60^{\circ} \mathrm{C}$ for $30 \mathrm{~s}$. HLA-DR 1 and DR4 subtypes were determined by group-specific amplification of HLA-DRB1 alleles using the primers DRBAMP-1 (5'-TTCTTGTGGCAGCTTAAGTT-3') and DRBAMP-4(5'-GTTTCTTGGAGCAGGTTAAAC-3') along with DRBAMP-B under the same PCR conditions (37). HLADRB3(DRw52) alleles were determined by PCR amplification with the primers DRBAMP-52 (5'-CCCAGCACGTTTCTTGGAGCT-3') and DRBAMP-B. HLA-DR2-DRB1 alleles were determined as has been described elsewhere (43).

18-mer oligonucleotide probes, supplied by the 11 th International Histocompatibility Testing Workshop, were used to detect polymorphic sequences around positions $28,37,57,70$, and 86 of the DRB1 first domain to distinguish HLA-DR1(DRB1 *0101-*0103), DR4(DRB1 *0401-*0411), and DRB3(DRw52) alleles, as well as DRB1 *1101, *1102, *1103, and *1104 (as well as subtypes of HLADR3, DRw6, and DRw8) similar to those described elsewhere $(52,53)$.
For HLA-DQA1 typing, genomic DNA was amplified with the primer pair DQAAMP-A (5'-ATGGTGTAAACTTGTACCAGT-3') and DQAAMP-B (5'-TTGGTAGCAGCGGTAGAGTTG-3') under conditions outlined for DRB, except the annealing step for the PCR was for $1 \mathrm{~min}$ at $55^{\circ} \mathrm{C}$. Oligonucleotide probes corresponding to the polymorphisms at positions $25,34,55$, and 69 were used for the hybridizations as supplied by the 11 th International Histocompatibility Testing Workshop.

For HLA-DQB1 typing, the primers used included DQBAMP-A (5'-CATGTGCTACTTCACCAACGG-3') and DQBAMP-B (5'CTGGTAGTTGTGTCTGCACAC-3') under the same PCR conditions as the DQA1 primers. Oligonucleotide probes corresponding to the polymorphic codons $26,37,45,49,57$, and 70 were used for dot blot hybridization.

Statistical analyses. Comparisons of HLA specificities and allelic frequencies in antitopo I-positive versus antitopo I-negative PSS patients and normal race-matched controls were performed using the chi square analysis of $2 \times 2$ tables and Yates' correction with the EPI-INFO statistical program. When one of the groups being analyzed contained five or less members, a two-tailed Fisher's exact test was used. Significant $P$ values were corrected $(\mathrm{pc})$ by multiplying the number of comparisons, i.e., for DR specificities $\times 12$, DQ specificities $\times 8$, DRB1 alleles $\times 40$, DQA 1 alleles $\times 7$, DQB1 alleles $\times 12$, and DPB1 alleles $\times 19$. Where an association with a particular specificity had been reported previously, the $P$ value was not corrected. Odds ratios (OR) were also determined from the same $2 \times 2$ tables.

\section{Results}

Scleroderma-related autoantibody frequencies. Of the 132 Caucasians with PSS examined, antitopo I autoantibodies were found in $21(16 \%)$. No significant differences occurred in the frequencies of antitopo I in Caucasian patients from Houston, Ottawa, and Miami. On the other hand, antitopo I antibodies were found in $38 \%$ of the 29 American blacks with PSS, a frequency that was significantly increased in blacks compared with Caucasians, as we have reported previously (54). All but three of the patients with antitopo I were positive by both immunodiffusion and immunoblotting, with three being positive by immunoblotting only. ACAs were found in only one black PSS patient, a frequency significantly less than the $36 \%$ seen in Caucasians (54).

Clinical differences between autoantibody subgroups. Medical records were retrospectively reviewed in $126(95 \%)$ of the 132 Caucasians with PSS. Differences in clinical features between the autoantibody subsets of PSS are shown in Table I. Proximal/diffuse scleroderma (skin involvement proximal to the metacarpophalangeal joints) and interstitial pulmonary disease were significantly less frequent in Caucasians with ACA than in PSS patients lacking this autoantibody (the latter reflecting what has been observed elsewhere [32]).

Among 28 American blacks in whom medical records were reviewed, diffuse or proximal scleroderma and interstitial pulmonary fibrosis were slightly more frequent in those with antitopo I than in those without, although the differences were not significant, perhaps because of the small numbers examined (clinical data were not available on the one black with ACAs).

HLA class II frequencies in Caucasians. All but five Caucasian PSS patients and 10 controls had sufficient genomic DNA available for oligotyping. In the few remaining patients and controls, HLA-DRB1, DQA1, and DQB1 alleles were determined by RFLP analysis, with alleles being assigned by linkage disequilibrium with characteristic RFLP patterns (44). 
Table I. Clinical Features in Autoantibody Subsets of Progressive Systemic Sclerosis

\begin{tabular}{|c|c|c|c|}
\hline & Antitopo $\mathrm{I}^{*}$ & $\mathrm{ACA}^{*}$ & Other PSS \\
\hline Caucasians & $(n=21)$ & $(n=45)$ & $(n=62)$ \\
\hline $\begin{array}{l}\text { Proximal/diffuse } \\
\text { scleroderma }^{\ddagger *}\end{array}$ & $18(86 \%)$ & $18(40 \%)^{\ddagger}$ & $47(77 \%)$ \\
\hline Pulmonary fibrosis & $12(57 \%)$ & $1(2 \%)^{\ddagger}$ & $23(37 \%)$ \\
\hline Renal involvement ${ }^{\S}$ & $1(5 \%)^{\|}$ & $1(2 \%)^{\prime \prime}$ & $7(11 \%)$ \\
\hline Myositis & $0(0 \%)$ & $0(0 \%)$ & $9(15 \%)$ \\
\hline American blacks & $(n=11)$ & $(n=0)$ & $(n=17)$ \\
\hline $\begin{array}{c}\text { Proximal/diffuse } \\
\text { scleroderma* }\end{array}$ & $11(100 \%)$ & - & $14(82 \%)$ \\
\hline Pulmonary fibrosis & $7(64 \%)$ & - & $6(35 \%)$ \\
\hline Renal involvement ${ }^{\S}$ & $0(0 \%)$ & - & $3(18 \%)$ \\
\hline Myositis & $0(0 \%)$ & - & $3(18 \%)$ \\
\hline
\end{tabular}

* Defined as skin involvement proximal to metacarpophalangeal joints. ${ }^{\ddagger} P<0.001$ compared with either antitopo I-positive or AACA-positive patients. ${ }^{8}$ Defined as rapidly progressive renal insufficiency and hypertension. "Including one patient with both ACA and antitopo I, who had sclerodermatous renal involvement.

HLA-DR and DQ specificities and alleles did not differ significantly between those with or without proximal/diffuse scleroderma (data not shown). HLA-DQw5 was marginally decreased in those with interstitial pulmonary fibrosis ( 24 vs. $48 \%$ in those without, $P=0.02$ uncorrected). This probably reflected the fact that HLA-DQw5 was weakly associated in this group with ACAs ( 55 vs. $31 \%$ in ACA-negative PSS patients, $P=0.01$ uncorrected, and vs. $34 \%$ in controls, $P=0.008$ uncorrected), which were nearly absent in those with interstitial pulmonary fibrosis. No significant differences in HLA-DR or DQ frequencies were found in those with renal or gastrointestinal involvement or pulmonary hypertension, although the small numbers of patients in these groups ( $<10$ in each) prevented meaningful statistical analysis.

The frequencies of HLA-DR2(DRB1*1501-*1602), DR4(DRB1 *0401-*0405) and DR5(DRw11)(DRB1*1101*1104) were increased in Caucasian PSS patients with antitopo I compared with either PSS patients lacking antitopo I or ACAs (other PSS patients in Tables II and III) or controls, although only the broad specificity HLA-DR5(DRB1*1101-*1104) achieved statistical significance. It should be noted that ACApositive PSS patients were considered separately because of the association of this autoantibody response also with HLADQB1 *0301 (DQw7) (37) ( Table III).

Oligotyping for subtypes of HLA-DR5(DRw11) showed equivalent frequencies of DRB $1 * 1101-* 1104$ in antitopo I positives and race-matched controls (Table II). Similarly, HLA-DR2(DRB1*1501-1602) and DR4(DRB1*0401-*0411) subtypes did not differ significantly between antitopo I-positive patients and racially matched controls.

HLA-DQB 1 *0301 (DQw7) was increased in frequency in Caucasians with antitopo I compared with other PSS patients $(P=0.02)$, as well as to Caucasian controls $(P=0.009)$, although these comparisons did not withstand correction for the number of variables examined $(n=8)$ (Table III). HLADQB1 *0302(DQw8) and DQB1 *0303(DQw9) were also in-
Table II. HLA-DRBI Frequencies in Autoantibody Subsets of Progressive Systemic Sclerosis in Caucasians

\begin{tabular}{|c|c|c|c|c|}
\hline HLA-DRB1 & $\begin{array}{c}\text { Antitopo } I^{\ddagger} \\
(n=21)\end{array}$ & $\begin{array}{c}\mathrm{ACA}^{\ddagger} \\
(n=47)\end{array}$ & $\begin{array}{l}\text { Other PSS } \\
(n=65)\end{array}$ & $\begin{array}{c}\text { Controls } \\
(n=200)\end{array}$ \\
\hline${ }^{*} 0101(\mathrm{DR} 1)^{\S}$ & $1(5 \%)$ & $14(30 \%)$ & $12(18 \%)$ & $35(18 \%$ \\
\hline *0102(DR1) & $1(5 \%)$ & $5(11 \%)$ & $4(6 \%)$ & $9(5 \%)$ \\
\hline *0103(DR1) & $1(5 \%)$ & $2(4 \%)$ & $2(3 \%)$ & $12(6 \%)$ \\
\hline *1501(DR2) & $7(33 \%)$ & $6(13 \%)$ & $11(17 \%)$ & $51(26 \%)$ \\
\hline *1502(DR2) & $0(0 \%)$ & $0(0 \%)$ & $1(2 \%)$ & $5(3 \%)$ \\
\hline *1601(DR2) & $1(5 \%)$ & $3(6 \%)$ & $0(0 \%)$ & $3(2 \%)$ \\
\hline *1602(DR2) & $0(0 \%)$ & $0(0 \%)$ & $1(2 \%)$ & $0(0 \%)$ \\
\hline *0301(DR3) & $3(14 \%)$ & $6(13 \%)$ & $25(38 \%)$ & $40(20 \%)$ \\
\hline *0401(DR4) & $4(19 \%)$ & $8(17 \%)$ & $7(11 \%)$ & $29(15 \%)$ \\
\hline *0402(DR4) & $1(5 \%)$ & $1(2 \%)$ & $2(3 \%)$ & $5(3 \%)$ \\
\hline *0403(DR4) & $0(0 \%)$ & $4(9 \%)$ & $2(3 \%)$ & $6(3 \%)$ \\
\hline *0404(DR4) & $2(10 \%)$ & $1(2 \%)$ & $4(6 \%)$ & $7(4 \%)$ \\
\hline *0405(DR4) & $2(10 \%)$ & $0(0 \%)$ & $0(0 \%)$ & $1(1 \%)$ \\
\hline *0407(DR4) & $0(0 \%)$ & $4(9 \%)$ & $0(0 \%)$ & $5(3 \%)$ \\
\hline *0408(DR4) & $0(0 \%)$ & $0(0 \%)$ & $1(2 \%)$ & $2(1 \%)$ \\
\hline *1101-*1104(DR5) & $10(48 \%)^{\| 1 / 1}$ & $14(30 \%)$ & $9(14 \%)$ & $21(11 \%)$ \\
\hline${ }^{*} 1101(\mathrm{DR} 5)$ & $6(29 \%)$ & $7(15 \%)$ & $3(5 \%)$ & $13(7 \%)$ \\
\hline *1102(DR5) & $0(0 \%)$ & $0(0 \%)$ & $2(3 \%)$ & $2(1 \%)$ \\
\hline *1103(DR5) & $1(5 \%)$ & $1(2 \%)$ & $0(0 \%)$ & $2(1 \%)$ \\
\hline *1104(DR5) & $3(14 \%)$ & $7(15 \%)$ & $5(8 \%)$ & $5(3 \%)$ \\
\hline *1201(DR5) & $0(0 \%)$ & $0(0 \%)$ & $1(2 \%)$ & $1(1 \%)$ \\
\hline *1301(DRw6) & $0(0 \%)$ & $3(6 \%)$ & $2(3 \%)$ & $27(14 \%)$ \\
\hline *1302(DRw6) & $1(5 \%)$ & $3(6 \%)$ & $7(11 \%)$ & $21(11 \%)$ \\
\hline *1303-*1305(DRw6) & $0(0 \%)$ & $0(0 \%)$ & $1(2 \%)$ & $2(1 \%)$ \\
\hline${ }^{*} 1401\left({ }^{*} \mathrm{DRw} 6\right)$ & $0(0 \%)$ & $3(6 \%)$ & $4(6 \%)$ & $9(5 \%)$ \\
\hline *1402(DRw6) & $1(5 \%)$ & $2(4 \%)$ & $2(3 \%)$ & $4(2 \%)$ \\
\hline *0701(DR7) & $5(24 \%)$ & $3(6 \%)$ & $13(20 \%)$ & $41(21 \%)$ \\
\hline *0801(DRw8) & $1(5 \%)$ & $5(11 \%)$ & $4(6 \%)$ & $13(7 \%)$ \\
\hline *0802(DRw8) & $0(0 \%)$ & $0(0 \%)$ & $1(2 \%)$ & $0(0 \%)$ \\
\hline *0803(DRw8) & $0(0 \%)$ & $2(4 \%)$ & $0(0 \%)$ & $1(1 \%)$ \\
\hline *0804(DRw8) & $0(0 \%)$ & $0(0 \%)$ & $4(6 \%)$ & $4(2 \%)$ \\
\hline *0901(DR9) & $0(0 \%)$ & $0(0 \%)$ & $1(2 \%)$ & $4(2 \%)$ \\
\hline
\end{tabular}

${ }^{\ddagger}$ One patient had both ACA and antitopo I, associated with HLADR3(DRw17), DQw2.1, and HLA-DRw8, DQw4 specificities and is included in both columns. ${ }^{\S}$ HLA-DR specificities composed of the respective HLA-DRB 1 alleles are shown in parentheses. HLADRB 1*0406, *0409-*0411(DR4), DRB1*1403-*1405(DRw6), and DRB1*1001(DRw10) were found in none of the patients and are thus not shown. " $P=0.002$, OR $=6$ compared with other PSS patients. ' $P=0.00001, \mathrm{OR}=8$ compared with other PSS controls.

creased, but again not significantly. Of the nine HLADQB 1 *0301 (DQw7)-negative Caucasian PSS patients with antitopo I, six (67\%) had either HLA-DQw8 or DQw9. Of the three remaining antitopo I-positive patients, one was homozygous for HLA-DQw6, one had DQw5 and DQw6, and the third had HLA-DQw2.1 and DQw4. The latter individual was the only PSS patient found to have both antitopo I and ACA autoantibodies. HLA-DQB1 *0301 (DQw7), *0302(DQw8) and ${ }^{*} 0303$ (DQw9) are the DQ $\beta$ chains that constitute the broad specificity DQw3, and this specificity was significantly increased in frequency compared with either other PSS patients and controls ( Table III). If the allelic frequency of HLA-DQw3 was considered, statistical significance was maintained, even 
Table III. HLA-DQA1 and DQB1 Frequencies in Autoantibody Subsets of Progressive Systemic Sclerosis in Caucasians

\begin{tabular}{|c|c|c|c|c|}
\hline & $\begin{array}{c}\text { Antitopo } I^{\ddagger} \\
(n=21)\end{array}$ & $\begin{array}{c}\mathrm{ACA}^{\ddagger} \\
(n=47)\end{array}$ & $\begin{array}{l}\text { Other PSS } \\
(n=65)\end{array}$ & $\begin{array}{l}\text { Controls } \\
(n=200)\end{array}$ \\
\hline \multicolumn{5}{|l|}{ HLA-DQA1 } \\
\hline$*^{*} 0101$ & $3(14 \%)^{8}$ & $25(53 \%)$ & $22(34 \%)$ & $64(32 \%)$ \\
\hline${ }^{*} 0102$ & $8(38 \%)$ & $12(26 \%)$ & $19(29 \%)$ & $74(37 \%)$ \\
\hline${ }^{*} 0103$ & $1(5 \%)$ & $3(6 \%)$ & $3(5 \%)$ & $35(17 \%)$ \\
\hline${ }^{*} 0201$ & $2(10 \%)$ & $3(6 \%)$ & $14(22 \%)$ & $40(20 \%)$ \\
\hline *03 & $9(43 \%)$ & $16(34 \%)$ & $19(29 \%)$ & $61(32 \%)$ \\
\hline$* 0401$ & $1(5 \%)$ & $5(11 \%)$ & $5(8 \%)$ & $12(6 \%)$ \\
\hline$* 0501$ & $13(62 \%)$ & $18(38 \%)$ & $35(54 \%)$ & $71(36 \%)$ \\
\hline \multicolumn{5}{|l|}{ HLA-DQB 1} \\
\hline${ }^{*} 0501-{ }^{*} 0503(\mathrm{DQw} 5 / \mathrm{DQw1})^{*}$ & $4(19 \%)$ & $26(55 \%)$ & $23(35 \%)$ & $67(34 \%)$ \\
\hline *0501 & $3(14 \%)$ & $21(45 \%)$ & $18(28 \%)$ & $57(29 \%)$ \\
\hline${ }^{*} 0502$ & $1(5 \%)$ & $2(4 \%)$ & $0(0 \%)$ & $3(2 \%)$ \\
\hline${ }^{*} 0503$ & $0(0 \%)$ & $4(9 \%)$ & $4(6 \%)$ & $8(4 \%)$ \\
\hline${ }^{*} 0601-{ }^{*} 0604(\mathrm{DQw} 6 / \mathrm{DQw1})^{*}$ & $8(38 \%)$ & $12(26 \%)$ & $22(34 \%)$ & $102(51 \%)$ \\
\hline$* 0601$ & $0(0 \%)$ & $2(4 \%)$ & $1(2 \%)$ & $5(3 \%)$ \\
\hline${ }^{*} 0602$ & $7(33 \%)$ & $6(13 \%)$ & $11(17 \%)$ & $52(26 \%)$ \\
\hline${ }^{*} 0603$ & $0(0 \%)$ & $2(4 \%)$ & $2(3 \%)$ & $32(16 \%)$ \\
\hline${ }^{*} 0604$ & $1(5 \%)$ & $3(6 \%)$ & $8(12 \%)$ & $23(12 \%)$ \\
\hline${ }^{*} 0201(\mathrm{DQw} 2)^{*}$ & $5(24 \%)$ & $7(15 \%)$ & $33(51 \%)$ & $72(36 \%)$ \\
\hline${ }^{*} 0301-* 0303(\mathrm{DQw} 3)^{*}$ & $18(86 \%)^{\| 1}$ & $29(62 \%)$ & $31(48 \%)$ & $92(46 \%)$ \\
\hline *0301(DQw7/DQw3)* & $12(57 \%)$ & $25(53 \%)^{* * \neq \pm}$ & $17(26 \%)$ & $54(27 \%)$ \\
\hline *0302(DQw8/DQw3)* & $7(33 \%)$ & $7(15 \%)$ & $12(18 \%)$ & $34(17 \%)$ \\
\hline *0303(DQw9/DQw3)* & $3(14 \%)$ & $2(4 \%)$ & $5(8 \%)$ & $10(5 \%)$ \\
\hline *0402(DQw4)* & $1(5 \%)$ & $5(9 \%)$ & $5(8 \%)$ & $13(7 \%)$ \\
\hline
\end{tabular}

* Numbers in parentheses refer to specific/broad HLA-DQ specificities composed of the DQB1 allele shown. No patients had HLA-DQA1*0601 (not shown). ${ }^{\ddagger}$ One patient had both ACA and antitopo I, associated with HLA-DRB1*0301, DQA $1^{*} 0501, \mathrm{DQB} 1{ }^{*} 0201$, and HLA-DRB $1 * 0801$, $\mathrm{DQA} 1{ }^{*} 0401, \mathrm{DQB} 1{ }^{*} 0402$ and is included in both columns. ${ }^{8} \mathrm{pc}=0.04$ compared with ACA positive patients. " $\mathrm{pc}=0.04, \mathrm{OR}=6.6$ compared with other PSS patients. ' $\mathrm{pc}=0.016, \mathrm{OR}=6.7$ compared with controls. ${ }^{* *} P=0.009, \mathrm{OR}=3$ compared with other $\mathrm{PSS}$ patients. ${ }^{\ddagger} P=0.001, \mathrm{OR}=3$ compared with controls.

after correcting for the eight HLA-DQ specificities examined (57\% in antitopo I-positive vs. $29 \%$ in other PSS patients (pc $=0.01)$ and $26 \%$ in controls $[\mathrm{pc}=0.0004, \mathrm{OR}=3.8]$ ).

HLA-DQA1 alleles were of similar frequency in antitopo I-positive PSS patients, other PSS patients, and controls ( Table III), as were HLA-DPB1 allele frequencies (55). HLADRB3*0202(DRw52b) was also slightly increased in frequency in antitopo I-positive (52\%) compared with antitopo I-negative PSS patients ( $32 \%, P=\mathrm{NS})$ and controls $(21 \%, \mathrm{pc}$ $=0.012$ ) (data not shown). No differences in the frequencies of HLA-DR5(DRw11), DQB1 *0301(DQw7), and DQw3 were seen between patients from Texas, Ottawa, or Florida (data not shown).

HLA-class II frequencies in American blacks. All American black PSS patients and controls were typed for HLA class II alleles by oligotyping. Neither the extent of skin involvement nor the presence of interstitial pulmonary fibrosis correlated with HLA-DR or DQ specificities among American black PSS patients with antitopo I. On the other hand, the broad specificities HLA-DR4 (DRB1 ${ }^{*} 0401,{ }^{*} 0403,{ }^{*} 0407$ ) and DR5(DRB* $1101-* 1104)$ were both increased in frequency in black antitopo I-positive patients compared with other PSS patients or black controls, although not significantly so, perhaps because of the small number of black PSS patients (Table IV). HLA-
DR5(DRw11) and DR4 subtype frequencies did not significantly differ in the antitopo I-positive patients from that in the other PSS patients or controls. HLA-DQB1 *0301 (DQw7), however, was associated with the antitopo I response compared with both antitopo I-negative PSS patients and controls ( Table V). Of the two HLA-DQB1*0301(DQw7)-negative American black PSS patients, one had HLA-DQB1 0501 (DQw5) and DQB1 *0602(DQw6) and the other had HLADQB1 ${ }^{* 0201(D Q w 2)}$ and DQB1 *0402(DQw4). HLA-DQB1* 0602(DQw6) was actually decreased in frequency in antitopo I-positive vs.-negative PSS patients, although not significantly.

Localization of susceptibility to antitopo I to specific $H L A$ $D Q \ddot{B} 1$ sequences. As shown above, most of the Caucasian and American black PSS patients had HLA-DQB1 *0301 (DQw7), *0302(DQw8), or *0303(DQw9), which all constitute the broad specificity HLA-DQw3. Examination of the amino acid sequences of these alleles (Table VI) showed extensive amino acid sequence homology. The presence of HLA-DQB 1 *0601*0604(DQw6) or DQw4 in all antitopo I-positive patients who were negative for HLA-DQw3, as well as the decreased frequencies of HLA-DQw5 and DQw2.1, suggests an amino acid sequence shared by HLA-DQB1 alleles comprising HLADQw3, DQw4, and DQw6 specificities but not found in those 
Table IV. HLA-DRB1 Frequencies in Autoantibody Subsets of Progressive Systemic Sclerosis in American Blacks

\begin{tabular}{|c|c|c|c|}
\hline HLA-DRB1 & $\begin{array}{l}\text { Antitopo I } \\
(n=11)\end{array}$ & $\begin{array}{l}\text { Other PSS } \\
(n=18)\end{array}$ & $\begin{array}{l}\text { Controls } \\
(n=88)\end{array}$ \\
\hline *0102(DR1) & $1(9 \%)$ & $2(11 \%)$ & $8(9 \%)$ \\
\hline *1501(DR2) & $0(0 \%)$ & $1(5 \%)$ & $3(3 \%)$ \\
\hline *1502(DR2) & $0(0 \%)$ & $1(5 \%)$ & $0(0 \%)$ \\
\hline *1503(DR2) & $2(18 \%)$ & $6(33 \%)$ & $16(18 \%)$ \\
\hline *0301(DR3) & $0(0 \%)$ & $3(17 \%)$ & $9(10 \%)$ \\
\hline *0302(DR3) & $1(9 \%)$ & $2(11 \%)$ & $12(14 \%)$ \\
\hline *0401(DR4) & $1(9 \%)$ & $0(0 \%)$ & $3(3 \%)$ \\
\hline *0403(DR4) & $1(9 \%)$ & $0(0 \%)$ & $1(1 \%)$ \\
\hline *0407(DR4) & $1(9 \%)$ & $0(0 \%)$ & $1(1 \%)$ \\
\hline${ }^{*} 1101-* 1104(\mathrm{DR} 5)$ & $5(45 \%)$ & $3(17 \%)$ & $20(23 \%)$ \\
\hline *1101(DR5) & $3(27 \%)$ & $0(0 \%)$ & $11(13 \%)$ \\
\hline *1102(DR5) & $1(9 \%)$ & $3(17 \%)$ & $6(7 \%)$ \\
\hline *1104(DR5) & $1(9 \%)$ & $0(0 \%)$ & $2(2 \%)$ \\
\hline *1201(DR5) & $0(0 \%)$ & $1(5 \%)$ & $3(3 \%)$ \\
\hline *1301(DRw6) & $1(9 \%)$ & $2(11 \%)$ & $11(13 \%)$ \\
\hline *1302(DRw6) & $0(0 \%)$ & $3(17 \%)$ & $4(5 \%)$ \\
\hline *1303(DRw6) & $1(9 \%)$ & $0(0 \%)$ & $5(6 \%)$ \\
\hline *1402(DRw6) & $0(0 \%)$ & $1(5 \%)$ & $4(5 \%)$ \\
\hline *0701(DR7) & $1(9 \%)$ & $2(11 \%)$ & $22(25 \%)$ \\
\hline *0802(DRw8) & $2(18 \%)$ & $0(0 \%)$ & $3(3 \%)$ \\
\hline *0803(DRw8) & $1(9 \%)$ & $0(0 \%)$ & $2(2 \%)$ \\
\hline *0804(DRw8) & $1(9 \%)$ & $4(22 \%)$ & $6(7 \%)$ \\
\hline *0901(DR9) & $0(0 \%)$ & $2(11 \%)$ & $0(0 \%)$ \\
\hline *1001(DRw10) & $0(0 \%)$ & $1(5 \%)$ & $4(5 \%)$ \\
\hline
\end{tabular}

${ }^{\ddagger}$ HLA-DR specificities composed of the respective HLA-DRB1 alleles are shown in parentheses. HLA-DRB1*0101, ${ }^{*} 0103,{ }^{*} 1601$, ${ }^{*} 1602,{ }^{*} 0402,{ }^{*} 0404-{ }^{*} 0406,{ }^{*} 0408-{ }^{*} 0411,{ }^{*} 1103,{ }^{*} 1401$, and ${ }^{*} 0801$ were found in none of the patients and their frequencies are thus not shown.

comprising DQw5 or DQw2. Several possible candidate sequences thereof derived from Table VI are shown in Table VII. One, a tyrosine residue at position 30 (tyr-30), is shared by HLA-DQB $1{ }^{*} 0402,{ }^{*} 0601,{ }^{*} 0602$, as well as by DQB $1{ }^{*} 0301$, ${ }^{*} 0302$, and ${ }^{*} 0303$. An HLA-DQB1 allele bearing tyr-30 was present in $100 \%$ of antitopo I-positive Caucasians compared with $66 \%$ of other PSS patients and $70 \%$ of Caucasian controls ( $\mathrm{pc}<0.01$ in both cases). HLA-DQB1-tyr-30 was likewise found in $100 \%$ of American black antitopo I-positive PSS patients. The allelic frequency of HLA-DQB1-tyr-30 was also slightly more frequent in American blacks with antitopo I $(80 \%)$ versus black PSS patients without antitopo I (61\%), although this difference was not statistically significant, perhaps because of the small numbers studied.

Alternatively, other polymorphic amino acids residues are shared by these HLA-DQB1 alleles, including methionine in position 14 , alanine in position 38 , and threonine in position 77. Each of these occurred in $100 \%$ of the antitopo I-positive Caucasians ( Table VII) and blacks. Unlike tyrosine at position 30 , however, none of these residues was statistically significantly increased in antitopo I-positive patients compared with other PSS patients and normal controls. Nonetheless, a role for one or more of these residues in susceptibility to this autoimmune response cannot be excluded.
Table V. HLA-DQAl and DQBI Frequencies in Autoantibody Subsets of Progressive Systemic Sclerosis in American Blacks

\begin{tabular}{|c|c|c|c|}
\hline & $\begin{array}{c}\text { Antitopo I } \\
(n=11)\end{array}$ & $\begin{array}{l}\text { Other PSS } \\
(n=18)\end{array}$ & $\begin{array}{l}\text { Controls } \\
(n=88)\end{array}$ \\
\hline \multicolumn{4}{|l|}{ HLA-DQA1 } \\
\hline${ }^{*} 0101$ & $3(27 \%)$ & $3(17 \%)$ & $28(32 \%)$ \\
\hline *0102 & $3(27 \%)$ & $8(44 \%)$ & $26(30 \%)$ \\
\hline *0103 & $0(0 \%)$ & $2(11 \%)$ & $16(18 \%)$ \\
\hline$* 0201$ & $1(9 \%)$ & $3(17 \%)$ & $24(27 \%)$ \\
\hline$* 03$ & $4(36 \%)$ & $2(11 \%)$ & $13(15 \%)$ \\
\hline$* 0401$ & $4(36 \%)$ & $6(33 \%)$ & $19(22 \%)$ \\
\hline *0501 & $5(45 \%)$ & $8(44 \%)$ & $33(38 \%)$ \\
\hline \multicolumn{4}{|l|}{ HLA-DQB1 } \\
\hline${ }^{*} 0501(\mathrm{DQw} 5 / \mathrm{DQw} 1)^{\ddagger}$ & $4(36 \%)$ & $3(17 \%)$ & $21(24 \%)$ \\
\hline${ }^{*} 0601-{ }^{*} 0604(\mathrm{DQw} 6 / \mathrm{DQw} 1)^{\ddagger}$ & $3(27 \%)$ & $11(61 \%)$ & $40(45 \%)$ \\
\hline *0601 & $1(9 \%)$ & $1(6 \%)$ & $4(5 \%)$ \\
\hline$* 0602$ & $1(9 \%)$ & $9(50 \%)$ & $16(18 \%)$ \\
\hline *0604 & $1(9 \%)$ & $3(17 \%)$ & $7(8 \%)$ \\
\hline${ }^{*} 0201(\mathrm{DQw} 2)^{\ddagger}$ & $2(18 \%)$ & $7(39 \%)$ & $30(34 \%)$ \\
\hline${ }^{*} 0301(\mathrm{DQ} w 7 / \mathrm{DQw} 3)^{\ddagger}$ & $9(82 \%)^{\xi \|}$ & $7(39 \%)$ & $29(33 \%)$ \\
\hline${ }^{*} 0303(\mathrm{DQw} 9 / \mathrm{DQw3})^{\ddagger}$ & $0(0 \%)$ & $1(5 \%)$ & $3(3 \%)$ \\
\hline${ }^{*} 0402(\mathrm{DQw})^{\ddagger}$ & $3(27 \%)$ & $3(17 \%)$ & $14(16 \%)$ \\
\hline
\end{tabular}

‡ Numbers in parentheses refer to specific/broad HLA-DQ specificities composed of the DQB1 allele shown. No patients had HLADQA $1 * 0601, \mathrm{DQB} 1 * 0502, \mathrm{DQB} 1{ }^{*} 0503, \mathrm{DQB} 1{ }^{*} 0603$, or

DQB1*0302 (not shown). ${ }^{\S} P=0.05$, OR $=7$ (uncorrected) compared with other PSS patients. " $\mathrm{pc}=0.02, \mathrm{OR}=9.2$ compared with controls.

The association of antitopo I with HLA-DQB1 rather than HLA-DRB1 or DRB3 alleles is further underscored by examining antitopo I-positive versus -negative PSS patients and controls who were negative for HLA-DR5(DRw11). The allelic frequency of HLA-DQB1 *0301 (DQw7) was $21 \%$ in 17 HLADR5(DRw11)-negative, antitopo I-positive Caucasian and American black PSS patients compared with 9\% in antitopo I-negative PSS patients and $10 \%$ in race-matched controls $(P$ $=$ NS for both groups). The allelic frequency of the broader specificity HLA-DQw3 was 47\% in HLA-DR5 (DRw1 1 )-negative Caucasian and American black antitopo I-positive PSS patients compared with $20 \%$ in antitopo I-negative patients $(P$ $=\mathrm{NS})$ and $25 \%$ in controls $(P=0.04)$. On the other hand, HLA-DQB1-tyr-30-bearing alleles occurred in $68 \%$ of 34 HLA-DR5(DRw11)-negative, antitopo I-positive patient haplotypes compared with $40 \%$ of 142 antitopo I-negative PSS patient haplotypes $(P=0.03)$ and $60 \%$ of control haplotypes $(P=$ NS). Evaluation of a possible HLA-DR5(DRw11) association independent of HLA-DQB1 ${ }^{*} 0301(\mathrm{DQw} 7)$, DQw3, or DQB1-tyr-30 was complicated by the finding that only two PSS patients had an HLA-DR5-bearing allele not associated with HLA-DQB 1 ${ }^{*} 0301$ (DQw7), one with HLA-DQB1*0602(DQw6) (antitopo I positive) and another with HLA-DQB1*0201 (DQw2) (antitopo I negative).

That HLA-DQ and not DR genes represent the primary MHC class II association with the antitopo I response is further suggested by the presence of HLA-DQB $1{ }^{*} 0301(\mathrm{DQw} 7)$ in all three native American Choctaw PSS patients found to have antitopo I. Two were homozygous for HLA-DQB1 ${ }^{*} 0301$ 


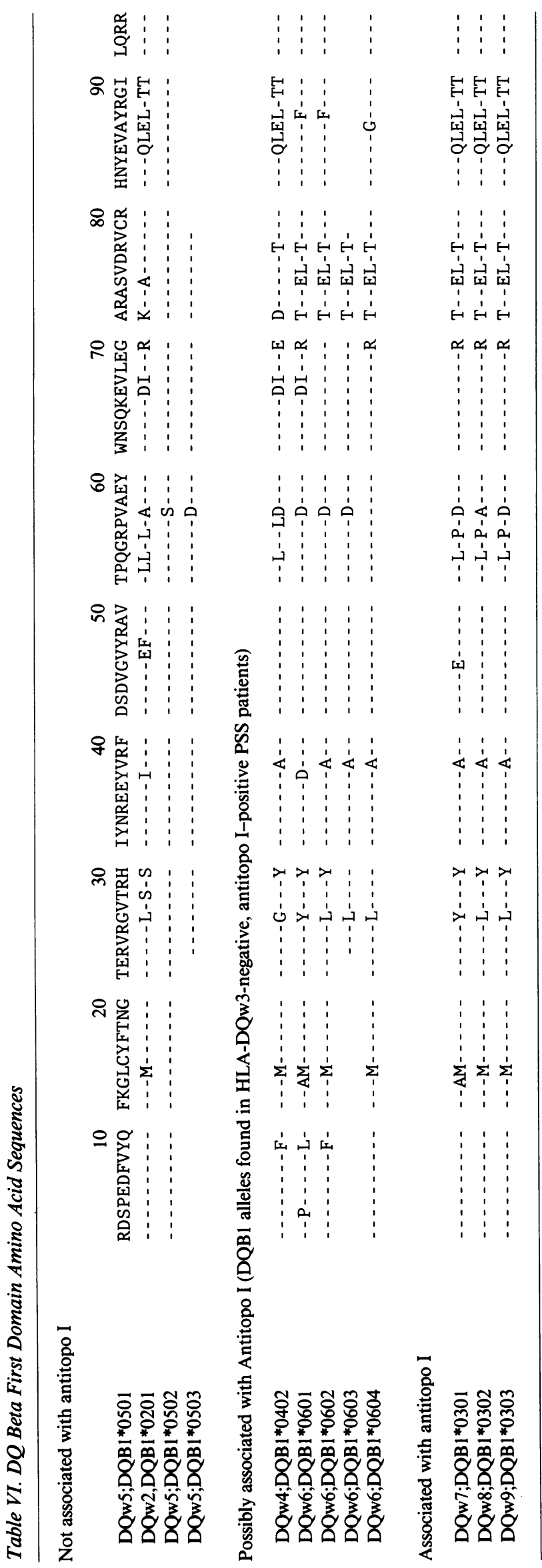

(DQw7) and the third had this allele and DQw4. Only one of these had HLA-DR5(DRw11). Instead, two had HLADQB $1 * 0301(\mathrm{DQw} 7)$ associated with the rare DRB1*1602 subtype of HLA-DR2.

\section{Discussion}

Our data suggest that the broad specificity HLA-DQw3 is most strongly associated with the antitopo I response. HLA-DQw3 comprises HLA-DQB ${ }^{*} 0301(\mathrm{DQw} 7)$ (linked to HLADR5(DRw11) as well as other DR specificities), DQw8 (associated with HLA-DR4), and DQw9 (associated with HLADR9 and occasionally HLA-DR7) (56). The HLA-DQB1 alleles comprising HLA-DQw3 share striking sequence homology (Table VI). All remaining HLA-DQw3-negative antitopo I-positive PSS patients had HLA-DQw6 (specifically HLA-DQB1*0602), which is found on HLA-DR2(DRB1*1501) haplotypes (among others), or DQw4, associated in Caucasians with HLA-DRw8(DRB1*0801, *0802) and in blacks with HLA-DRw8 and HLA-DR3(DRB1 *0302). HLA-DQw3 (DQB1 *0301, *0302, and *0303), DQw6 (DQB1 *0602), and DQw4 (DQB1*0402) share specific amino acid residues not found in the same position on other HLA-DQB1 alleles. In the second hypervariable region, for example, there is a polar uncharged tyrosine residue at position 30 (tyr-30), as opposed to a polar uncharged serine or a positively charged histidine. At position 38 there is a hydrophobic alanine (ala-38) as opposed to a hydrophobic valine residue. In the third hypervariable region there is a polar uncharged threonine at position 77 (thr77 ) as opposed to a positively charged arginine. Analysis of the frequencies of alleles bearing these residues suggests the strongest association of these to be with tyr-30 alleles. Thus although HLA-DQw3 (especially the DQB1*0301(DQw7) subtype thereof) is most strongly associated with the antitopo I response, the ubiquity of tyr-30-bearing DQB1 alleles in HLADQw3 negatives suggests that HLA-DQB1-tyr-30 may form the minimum requirement for the antitopo I response. We cannot exclude the possibility, however, that one or more of the other shared polymorphic sequences in $\mathrm{DQB} 1$ alleles may also play important roles.

These data, then, allow a reinterpretation of previous apparently conflicting reports of serologically defined HLA class II allele frequencies in PSS. Differences in autoantibody frequencies in the different patient groups reported could explain at least in part some of these discrepancies. For example, reports of an increased frequency of HLA-DR 1 (13-16) could be from patient populations with a higher frequency of ACA, or associations with HLA-DR3 (and perhaps even C4 null alleles, which are linked to HLA-DR3 [11, 17, 19]) could reflect a higher frequency of anti-PM-Scl. Other reports showing associations with HLA-DR5 $(16,18-20)$ could be explained by a higher proportion of patients with antitopo I and/or ACA.

Apparent discrepancies of HLA-DR associations with autoantibody subsets of PSS also could be better explained by their linkage disequilibrium with certain HLA-DQ alleles, which in fact may be the primary associations. For example, different reports have linked the ACA response to HLA-DR 1 alone (27), DR1, DR4, and/or DRw8 (36), and DR5(DRw11) (20). These HLA-DR specificities share no common unique amino acid sequences (57). However, DNA analyses from our own laboratory (37) have shown stronger 
Table VII. Phenotypic and Genotypic Frequencies of $H L A-D Q B 1$ Amino Acid Residues in Caucasian Progressive Systemic Sclerosis Patients

\begin{tabular}{lcccc}
\hline \multicolumn{1}{c}{ HLA-DQB1 } & Antitopo* & ACA $^{*}$ & $\begin{array}{c}\text { Other } \\
\text { PSS }\end{array}$ & Controls \\
\hline Phenotypic & $(n=21)$ & $(n=47)$ & $(n=65)$ & $(n=200)$ \\
Meth 14 & $21(100 \%)$ & $44(93 \%)$ & $65(100 \%)$ & $196(98 \%)$ \\
Tyr 30 & $21(100 \%)^{\ddagger \S}$ & $38(80 \%)$ & $43(66 \%)$ & $140(70 \%)$ \\
Ala 38 & $21(100 \%)$ & $39(84 \%)$ & $50(77 \%)$ & $162(81 \%)$ \\
Thr 77 & $21(100 \%)$ & $40(86 \%)$ & $50(77 \%)$ & $164(82 \%)$ \\
TRAELDT 71-77 & $20(95 \%)$ & $39(84 \%)$ & $46(71 \%)$ & $164(82 \%)$ \\
Genotypic (allelic) & $(n=42)$ & $(n=94)$ & $(n=130)$ & $(n=400)$ \\
Meth 14 & $37(88 \%)$ & $66(70 \%)$ & $106(82 \%)$ & $328(82 \%)$ \\
Tyr 30 & $31(74 \%)^{\mid \text {|⿰ }}$ & $55(58 \%)$ & $55(42 \%)$ & $184(46 \%)$ \\
Ala 38 & $31(74 \%)$ & $57(61 \%)$ & $67(52 \%)$ & $236(59 \%)$ \\
Thr 77 & $31(74 \%)$ & $60(64 \%)$ & $68(52 \%)$ & $240(60 \%)$ \\
TRAELDT 71-77 & $32(76 \%)^{* *}$ & $55(58 \%)$ & $60(46 \%)$ & $228(57 \%)$
\end{tabular}

* Including one patient with both ACA and antitopo, associated with HLA-DR3 (DRw17), DQw2.1, and HLA-DRw8, DQw4 specificities and is included in both columns. ${ }^{\ddagger} \mathrm{pc}=0.007$ compared with "other PSS" patients. All $P$ values are corrected by multiplying by the five variables examined. ${ }^{\S} \mathrm{pc}=0.008$ compared with controls. " $\mathrm{pc}$ $=0.0035$ compared with other PSS patients. ' $\mathrm{pc}=0.005$ compared with controls. ${ }^{* *} \mathrm{pc}=0.005$ compared with other PSS patients.

associations of ACA with HLA-DQB1 alleles in linkage disequilibrium with these HLA-DR antigens: HLA-DQw5 (linked to HLA-DR 1); HLA-DQB1 *0301(DQw7) (found on most HLA-DR5 and many DR4-bearing haplotypes) (54), and HLA-DQw4 (found on most Caucasian HLA-DRw8 haplotypes). These HLA-DQ specificities have in common the presence of a polar amino acid residue at position 26 of the HLADQB1 outermost domain and have been found in all of the ACA-positive patients studied thus far (37).

Similarly, for the antitopo I response, the previous serologic HLA associations have been with HLA-DR2 (25) and DR5 $(27,36)$, which share no unique amino acid sequences $(57)$; however, HLA-DQB1*0602(DQw6) and HLA-DQB1*0301 (DQw7), which are in linkage disequilibrium with these DR specificities, respectively (55), share sequence homologies in their second and third hypervariable regions of the HLADQB1 outermost domain. These uniquely shared amino acid residues in these regions were found in all of the antitopo I-positive PSS patients.

The only patient with both ACA and antitopo I antibodies in this study was found to have HLA-DQw4, a specificity that possesses a polar amino acid at $\mathrm{DQB} 1$ position 26 and a tyrosine at DQB1 position 30 . Interestingly, HLA-DQB $1{ }^{*} 0301$ (DQw7) also possesses both of these potentially relevant $D Q B 1$ sequences and is increased in frequency in both ACA-positive and antitopo I-positive PSS patients, yet both autoantibodies rarely coexist in the same patient (27). An explanation for this near mutual exclusivity of autoantibody expression is not apparent, however, it suggests a role for non-HLA factors, either genetic or environmental, in triggering these autoimmune responses.

Still, there were some PSS patients who had HLA-DQB-tyr30 alleles and did not express antitopo I, although the converse was not found. One possible reason could be that the serum level of antitopo I antibodies they expressed were below those detectable by our immunodiffusion and immunoblotting assays. Alternatively, these patients may have lacked the appropriate $T$ cell receptor genes to whose products the HLA-DQ heterodimers could present the processed antitopo I autoantigen. Another alternative would be that the HLA associations are better explained by clinical subsets of PSS, which are themselves associated with antitopo antibodies. This was not found, however, in this study.

Finally, these data regarding antitopo I antibodies, as well as our previous studies of ACA, suggest that scleroderma, similar to systemic lupus erythematosus (58), can be viewed as a composite disease of several HLA-DQ-associated autoantibody (and in turn clinical) subsets. Additional direct evidence that HLA-DQ mediates these autoimmune responses is needed, as well as studies to determine whether these highly specific autoantibodies participate in the pathogenesis of PSS.

\section{Acknowledgments}

We thank Karen Whittington, Hong Nguyen, Nancy Biggs, and Louise St. Jacques for technical assistance and Grace L. Griffin for preparation of this manuscript. We are also grateful to Dr. Robert Howard, Choctaw Nation Health Services Authority, Talihina, Oklahoma, for permitting us to study blood samples from his three native Americans with scleroderma.

This work was supported by a grant from the Scleroderma Research Foundation (\#1094) and a grant from the Scleroderma Foundation, Inc. (RG), as well as by National Institutes of Health grant AR39325 (JDR) and an Arthritis Foundation Clinical Research Center Grant. Dr. Goldstein is a Career Scientist of the Ontario Ministry of Health, Health Research Personnel Development Program. The results and conclusions are those of the authors and no official endorsement by the Ontario Ministry of Health is intended or should be inferred.

\section{References}

1. Lilis, R., H. Anderson, W. J. Nicholson, S. Daum, A. S. Fischbein, and I. J. Selikoff. 1975. The prevalence of disease amongst vinyl chloride polyvinyl chloride workers. Ann. NY Acad. Sci. 246:22-41.

2. Finch, W. R., G. P. Rodnan, R. B. Buckingham, R. K. Prince, and A. Winkelstein. 1980. Bleomycin-induced scleroderma. J. Rheumatol. 7:651-659.

3. Mateo, I. M., M. Izquierdo, M. P. Fernandez-Dapica, A. Cabello, and J. J. Gomez-Reino. 1984. Toxic epidemic syndrome: musculoskeletal manifestations. J. Rheumatol. 11:333-338.

4. Palestine, R. F., J. L. Millens, G. T. Spiegel, and A. L. Schroeter. 1980. Skin manifestations of pentazocine abuse. J. Am. Acad. Dermatol. 2:47-55.

5. Medsger, T. A., Jr., and A. T. Masi. 1971. Epidemiology of systemic sclerosis. Ann. Intern. Med. 74:714-721.

6. Buckman, K. J., S. K. Moore, A. J. Ebbin, M. D. Cox, and E. L. Dubois. 1978. Familial systemic lupus erythematosus. Arch. Intern. Med. 138:1674-1676.

7. Flores, R. H., M. B. Stevens, and F. C. Arnett. 1984. Familial occurrence of progressive systemic sclerosis and systemic lupus erythematosus. J. Rheumatol. 11:321-323.

8. Clements, P. J., G. Opelz, P. I. Terasaki, M. R. Mickey, and D. Furst. 1978. Association of HLA antigen A9 with progressive systemic sclerosis (scleroderma ). Tissue Antigens. 11:357-361.

9. Ercilla, M. G., F. Arriaga, M. R. Gratacos, J. Coll, V. Lecha, J. Vives, and R. Castillo. 1981. HLA antigens and scleroderma. Arch. Dermatol. Res. 271:381385 .

10. Hughes, P., K. Gelsthorpe, R. W. Doughty, N. R. Rowell, F. D. Rosenthal, and I. B. Sneddon. 1978. The association of HLA-B8 with visceral disease in systemic sclerosis. Clin. Exp. Immunol. 31:351-356.

11. Kallenberg, C. G. M., J. M. van der Voort-Beelen, J. d'Amaro, and T. H. The. 1981. Increased frequency of B8/DR3 in scleroderma and association with impaired cellular immune response. Clin. Exp. Immunol. 43:478-485.

12. Mollenhauer, E., R. Schmidt, M. Heinrichs, and C. Rittner. 1984. Scleroderma: possible significance of silent alleles at the C4B locus. Arthritis Rheum 27:711-712. 
13. Lynch, C. J., G. Singh, T. L. Whiteside, G. P. Rodnan, T. A. Medsger, and B. S. Rabin. 1982. Histocompatibility antigens in progressive systemic sclerosis (PSS; scleroderma). J. Clin. Immunol. 2:314-318.

14. DiBartolomeo, A. G., B. S. Rabin, and G. P. Rodnan. 1981. HLA-D antigens in progressive systemic sclerosis (scleroderma). Immunol. Commun. 10:733-740.

15. Black, C. M., K. I. Welsh, P. J. Maddison, M. I. V. Jayson, and R. M. Berstein. 1984. HLA antigens, autoantibodies and clinical subsets in scleroderma. Br. J. Rheumatol. 23:267-271.

16. Alarcon, G. S., R. M. Phillips, C. K. Wasner, R. T. Acton, and B. O. Barger. 1985. DR antigens in systemic sclerosis: lack of clinical correlations. Tissue Antigens. 26:156-158.

17. Germain, B. F., L. R. Espinoza, L. L. Bergen, M. Vagesh, and F. B. Vasey. 1981. Increased prevalence of DRw3 in the CREST syndrome. Arthritis Rheum. 24:857-859.

18. Gladman, D. D., E. C. Keystone, M. Baron, P. Lee, D. Cane, and H. Mervert. 1981. Increased frequency of DR5 in scleroderma. Arthritis Rheum. 24:854-856.

19. Briggs, D. C., K. Welsh, R. S. Pereira, and C. M. Black. 1986. A strong association between null alleles at the $\mathrm{C} 4 \mathrm{~A}$ locus in the major histocompatibility complex and systemic sclerosis. Arthritis Rheum. 29:1274-1277.

20. Dunckley, H., E. C. Jazwinska, P. A. Gatenby, and S. W. Serjeantson. 1989. DNA-DR typing shows HLA-DRw11 RFLPs are increased in frequency in both progressive systemic sclerosis and CREST variants of scleroderma. Tissue Antigens. 33:418-420.

21. Rabin, B. S., G. P. Rodnan, S. Bassion, and T. J. Gill. 1975. HLA antigens in progressive systemic sclerosis (scleroderma). Arthritis Rheum. 18:381-382. (Letter).

22. Crouzet, J., M. C. Marbach, J. P. Camus, P. Godeau, G. Herreman, D. Richier, J. Hors, and J. Dausset. 1975. Recherche d'une association entre antigenes HL-A et sclerodermie systemique. Presse Med. 4:2489-2492.

23. Birnbaum, N. S., G. P. Rodnan, B. S. Rabin, and S. Bassion. 1977. Histocompatibility antigens in progressive systemic sclerosis (scleroderma). J. Rheumatol. 4:425-428.

24. Niks, M., J. Rovensky, J. Nyulassy, M. Buc, J. Stefanovic, and D. Zitnan. 1982. Lack of association of HLA-DR antigens with progressive systemic sclerosis (scleroderma). Tissue Antigens. 19:238-239.

25. Livington, J. Z., T. E. Scott, F. M. Wigley, G. J. Anhalt, W. B. Bias, R. H. McLean, and M. C. Hochberg. 1987. Systemic sclerosis (scleroderma): clinical, genetic and serologic subsets. J. Rheumatol. 14:512-518.

26. Weiner, E. S., W. C. Earnshaw, J. L. Senécal, B. Bordwell, P. Johnson, and N. F. Rothfield. 1988. Clinical associations of anticentromere antibodies and antibodies to topoisomerase I: a study of 355 patients. Arthritis Rheum. 31:378385.

27. Steen, V. D., D. L. Powell, and T. A. Medsger, Jr. 1988. Clinical correlations and prognosis based on serum autoantibodies in patients with progressive systemic sclerosis. Arthritis Rheum. 31:196-203.

28. Fritzler, M. J., J. D. Kinsella, and E. Garbutt. 1980. The CREST syndrome: a distinct serologic entity with anticentromere antibodies. Am. J. Med. 69:520-526.

29. Tan, E. M., G. P. Rodnan, I. Garcia, Y. Moroi, M. J. Fritzler, and C. Peebles. 1980. Diversity of antinuclear antibodies in progressive systemic sclerosis: anti-centromere antibody and its relationship to CREST syndrome. Arthritis Rheum. 23:617-625.

30. Kallenberg, C. G. M., G. W. Pastoor, A. A. Wouda, and T. H. The. 1982. Antinuclear antibodies in patients with Raynaud's phenomenon: clinical significance of anticentromere antibodies. Ann. Rheum. Dis. 41:382-387.

31. Catoggio, L. J., R. P. Skinner, and P. J. Maddison. 1983. Frequency and clinical significance of anticentromere and anti-Scl-70 antibodies in an English connective tissue disease population. Rheumatol. Int. 3:19-21.

32. Steen, V. D., G. L. Ziegler, G. P. Rodnan, and T. A. Medsger, Jr. 1984. Clinical and laboratory associations of anticentromere antibody in patients with progressive systemic sclerosis. Arthritis Rheum. 27:125-131.

33. Nishikai, M., Y. Okano, H. Yamashita, and M. Watanabe. 1984. Characterization of centromere (kinetochore) antigen reactive with sera of patients with a scleroderma variant (CREST syndrome). Ann. Rheum. Dis. 43:819-824.

34. Reimer, G., V. D. Steen, C. A. Penning, T. A. Medsger, Jr., and E. M. Tan. 1988. Correlates between autoantibodies to nucleolar antigens and clinical features in patients with systemic sclerosis (scleroderma). Arthritis Rheum. 31:525532.

35. Shero, J. H., B. Bordwell, N. F. Rothfield, and W. C. Earnshaw. 1986. High titers of autoantibodies to topoisomerase I (Scl-70) in sera of scleroderma patients. Science (Wash. DC). 231:737-740.

36. Genth, E., R. Mierau, P. Genetzky, C. A. von Mühlen, S. Kaufman, H. von Wilmowsky, M. Meurer, T. Krieg, H. J. Pollman, and P. W. Hartl. 1990.
Immunogenetic associations of scleroderma-related antinuclear antibodies. $\mathrm{Ar}$ thritis Rheum. 33:657-665.

37. Reveille, J. D., D. Owerbach, R. Goldstein, R. Moreda, R. A. Isern, and F. C. Arnett. 1992. Association of polar amino acids at position 26 of the HLADQB1 first domain with the anticentromere autoantibody response in systemic sclerosis (scleroderma). J. Clin. Invest. 89:1208-1213.

38. Arnett, F. C., W. B. Bias, R. H. McLean, M. Engel, M. Duvic, R. Goldstein, L. Freni-Titulaer, T. W. McKinley, and M. C. Hochberg. 1990. Connective tissue disease in southeast Georgia. A community based study of immunogenetic markers and autoantibodies. J. Rheumatol. 17:1029-1035.

39. Subcommittee for Scleroderma Criteria of the American Rheumatism Association Diagnostic and Therapeutic Criteria Committee. 1980. Preliminary criteria for the classification of systemic sclerosis (scleroderma). Arthritis Rheum. 23:581-590.

40. Piccinini, G., E. Cardellini, G. Reimer, F. C. Arnett, and E. Durban. 1991. An antigenic region of topoisomerase I DNA polymerase chain reaction-generated fragment recognized by autoantibodies of scleroderma patients. Mol. Immunol. 28:333-339.

41. Blin, N., and D. W. Stafford. 1978. A general method for isolation of high molecular weight DNA from eukaroytes. Nucleic Acids Res. 3:2303-2308.

42. McDaniel, D. O., R. T. Acton, B. O. Barger, W. J. Koopman, and J. D. Reveille. 1987. Association of 9.2 kilobase PvuII class I major histocompatibility complex restriction fragment length polymorphism with ankylosing spondylitis. Arthritis Rheum. 30:894-900.

43. Moraes, M. E., M. Fernandez-Vina, and P. Stastny. 1991. DNA typing for Class II HLA antigens with allele-specific or group specific amplification. IV Typing for alleles of the HLA-DR2 group. Hum. Immunol. 31:139-144.

44. Cohen, D., M. Simons, J. M. Lalouel, and B. DuPont. 1988. Nomenclature for HLA-RFLP. Tenth International Histocompatibility Workshop Newsletter. 2:44-51.

45. Reveille, J. D., R. R. Schrohenloher, R. T. Acton, and B. O. Barger. 1989. DNA analysis of HLA-DR and DQ genes in American blacks with systemic lupus erythematosus. Arthritis Rheum. 32:1243-1251.

46. Reveille, J. D., R. T. Acton, K. Anderson, B. O. Barger, and R. E. Schrohenloher. 1990. RFLP analysis of HLA-DR, DQ, DP and C4 alleles in Caucasians with systemic lupus erythematosus. J. Rheumatol. 18:14-18.

47. Carlsson, B., J. Wallin, J. Bohme, and E. Moller. 1987. HLA-DR-DQ haplotypes defined by restriction fragment analysis: correlation to serology. Hum. Immunol. 20:95-113.

48. MacMurray, A. J., J. I. Bell, D. Denney, D. Watling, L. S. Foster, and H. O. McDevitt. 1987. Molecular mapping of class II polymorphisms in the human major histocompatibility complex. II. DQ $\beta$. J. Immunol. 139:574-586.

49. Bell, J. I., D. Denney, A. MacMurray, L. Foster, D. Watling, and H. O. McDevitt. 1987. Molecular mapping of class II polymorphisms in the human major histocompatibility complex. I. DR $\beta$. J. Immunol. 139:562-573.

50. Bidwell, J. L., E. A. Bidwell, D. A. Savage, D. Middleton, P. T. Klouda, and B. A. Bradley. 1988. A DNA-RFLP typing system that positively identifies serologically well defined and ill defined HLA-DR and DQ alleles, including DRw10. Transplantation (Baltimore). 45:640-646.

51. Bodmer, J. G., S. G. E. Marsh, P. Parham, H. A. Erlich, E. Albert, W. F. Bodmer, B. Dupont, B. Mach, W. R. Mayr, T. Sasazuki, et al. 1990. Nomenclature for factors of the HLA system. 1989. Hum. Immunol. 28:326-342.

52. Gao, X., M. Fernandez-Vina, W. Shumway, and P. Stastny. 1990. DNA typing for class II HLA antigens with allele specific or group-specific amplification. I. Typing for subsets of HLA-DR4. Hum. Immunol. 27:40-47.

53. Fernandez-Vina, M., W. Shumway, and P. Stastny. 1990. DNA typing for class II HLA antigens with allele-specific or group-specific amplification. II. Typing for alleles of the DRw52-associated group. Hum. Immunol. 28:51-64.

54. Reveille, J. D., E. Durban, R. Goldstein, R. Moreda, and F. C. Arnett. 1992. Racial differences in the frequencies of scleroderma-related autoantibodies. Arthritis Rheum. 35:216-218.

55. Reveille, J. D., J. Brady, M. MacLeod-St. Clair, E. Durban. 1992. HLADPB1 alleles and autoantibody subsets in systemic lupus erythematosus, Sjögren's syndrome and progressive systemic sclerosis: a question of disease relevance. Tissue Antigens. 40:45-48.

56. Bodmer, W. F., E. Albert, J. G. Bodmer, B. Dupont, B. Mach, W. R. Mayr, T. Sasazuki, G. M. Th. Schreuder, A. Svejgaard, and P. I. Terasaki. 1989. Nomenclature for factors of the HLA System, 1987. In Histocompatibility Testing 1987. Vol I. Immunobiology of HLA. B. Dupont, editor. Springer-Verlag, New York. 72-79.

57. Marsh, S. G. E., and J. G. Bodmer. 1990. HLA-DRB nucleotide sequences. Immunogenetics. 31:141-144.

58. Reveille, J. D., M. L. Olsen, and F. C. Arnett. 1990. Systemic lupus erythematosus (SLE): a composite disease of HLA-DQ associated autoantibody responses. Hum. Immunol. 22(Suppl.):40. 